\title{
A naturalização da violência obstétrica e as dificuldades do reconhecimento dos seus sinais
}

\section{The naturalization of obstetric violence and the difficulties of recognition of your signs}

\author{
${ }^{1}$ Maria Martha Rennó Ribeiro Chaves de Freitas mariamartha.renno@yahoo.com \\ ${ }^{2}$ Júlio César Soares Aragão
}

\section{RESUMO}

O presente artigo sustenta o objetivo de discorrer sobre a Violência Obstétrica como uma expressão da violência contra a mulher, considerando as desigualdades estabelecidas pelos papeis determinados para homens e mulheres na sociedade. Serão apresentados dados que reforçam que a violência institucional pode mascarar a identificação dos atos e condutas que caracterizam a Violência Obstétrica, sendo este um dos fatores que dificultam o reconhecimento das mulheres enquanto vítimas deste tipo de violência. Outro fator determinante para este processo consiste na inexpressiva quantidade de legislações promulgadas para o combate deste tipo de violência no Brasil. Diante deste contexto, serão apresentadas algumas informações obtidas por meio da realização da pesquisa "Violência Obstétrica e a Violação de Diretos Reprodutivos". Onze mulheres participantes de um programa de orientação à gestante em um Município do interior do Estado de São Paulo foram convidadas a participar desta pesquisa com características qualitativas. O objetivo geral da pesquisa consiste na identificação da ocorrência e quais os tipos de violência estão presentes nos discursos de vivências dos processos de pré-natal e do fenômeno do parto das mulheres que participam deste programa. Os relatos das mulheres apontam que parto representa um momento propício para a disseminação da violência, pois as usuários dos serviços de Saúde tendem a ter sua autonomia negada em detrimento das desigualdades apontadas anteriormente. Para que a Violência Obstétrica possa ser superada, torna-se necessário ampliar as legislações específicas e possibilitar que a população tenha acesso aos seus direitos, para que estes possam ser exercidos em respeito à autonomia e à dignidade humana.

Palavras-chave: Violência Obstétrica. Planejamento Familiar. Direitos Reprodutivos. Autonomia feminina.

\begin{abstract}
This article supports the objective of discussing Obstetric Violence as an expression of violence against women, considering the inequalities established by the roles determined for men and women in society. It will be presented data that reinforce that institutional violence can mask the identification of acts and behaviors that characterize Obstetric Violence, which is one of the factors that make it difficult to recognize women as victims of this type of violence. Another determining factor for this process is the inexpressive amount of legislation enacted to combat this type of violence in Brazil. Given this context, some information obtained through the research "Obstetric Violence and Breach of Reproductive Rights" will be presented. Eleven women participating in a program of guidance to pregnant women in a city in the interior of the State of São Paulo were invited to participate in this research with qualitative characteristics. The general objective of the research is to identify the occurrence and what types of violence are present in the discourses on the experiences of prenatal processes and the phenomenon of childbirth of women participating in this program. The women's reports indicate that childbirth represents a propitious moment for the spread of violence, since the users of the health services tend to have their autonomy denied to the detriment of the previously mentioned inequalities. In order for Obstetric Violence to be overcome, it is necessary to expand specific legislation and allow the population to have access to their rights, so that they can be exercised with respect for autonomy and human dignity.
\end{abstract}

Keywords: Obstetric Violence, Family Planning, Reproductive Rights, Female Autonomy.

1 Assistente Social graduada pelo Centro Universitário de Volta Redonda. Pós-graduada em Políticas Sociais e Trabalho Social com Famílias, pela Unitau. Mestranda em Ensino em Ciências da Saúde e do Meio Ambiente pelo Centro Universitário de Volta Redonda.

2 Centro Universitário de Volta Redonda - UniFOA. https://orcid.org/0000-0002-8210-6348 


\title{
1 INTRODUÇÃO
}

A Violência Obstétrica representa uma temática que vem sendo disseminada com cada vez mais frequência, principalmente pelos veículos midiáticos. Sua discussão tem sido promovida por meio de reportagens que envolvem a denúncia de mulheres que vivenciaram este tipo de violência, que se caracteriza por:

\begin{abstract}
Um problema recorrente presente nas práticas da atenção destinada à mulher no parto e envolve questões sociais como de gênero, de raça, de classe e institucional. Configura-se como violência, a imposição de intervenções danosas à integridade física e psicológica das mulheres nas instituições em que são atendidas, bem como o desrespeito a sua autonomia (MUNIZ;BARBOSA, 2012, p. 1).
\end{abstract}

A fim de promover a ampliação desta discussão, a Defensoria Pública do Estado de São Paulo produziu uma cartilha informativa no ano de 2014.Segundo esta cartilha, as formas mais comuns de Violência Obstétrica consistem em ações, tais quais:

- $\quad$ Recusa da admissão em hospital ou maternidade (peregrinação por leito);

- Impedimento da entrada do acompanhante escolhido pela mulher;

- Procedimentos que incidam sobre o corpo da mulher, que interfiram, causem dor ou dano físico (de grau leve a intenso). Exemplos: soro com ocitocina para acelerar o trabalho de parto por conveniência médica, exames de toque sucessivos e por diferentes pessoas, privação de alimentos, episiotomia (corte vaginal), imobilização (braços e pernas), etc;

- Toda ação verbal ou comportamental que cause na mulher sentimentos de inferioridade, vulnerabilidade, abandono, instabilidade emocional, medo, acuação, insegurança, dissuasão, ludibriamento, alienação, perda de integridade, dignidade e prestígio;

- Cesariana sem indicação clínica e sem consentimento da mulher;

- Impedir ou retardar o contato do bebê com a mulher logo após o parto, impedir o alojamento conjunto mãe e bebê, levando o recém-nascido para berçários sem nenhuma necessidade médica, apenas por conveniência da instituição;

- Impedir ou dificultar o aleitamento materno (impedindo a amamentação na primeira hora de vida, afastando o recém-nascido de sua mãe, deixando-o em berçários onde são introduzidas mamadeiras e chupetas etc) (BRASIL, 2014).

Barboza e Mota (2016, p. 122) apontam que a "violência simbólica que ocorre no cenário do parto é uma das faces da violência de gênero e frequentemente é considerada como parte da rotina dos serviços de saúde". Como tais condutas profissionais são instituídas e perpetuadas no ambiente hospitalar, as mulheres, usuárias dos serviços de Saúde tendem a acreditar que consistem em ações rotineiras e habituais, desvinculando estas experiências ao cenário da violação de direitos e da violência contra a mulher. Considerar que estas ações coercitivas e arbitrárias são parte natural do processo de atendimento da política de Saúde pode dificultar o reconhecimento das mulheres enquanto vítimas deste tipo de violência.

O reflexo do processo de naturalização da Violência Obstétrica pode ser demonstrado por resultados de pesquisas os quais apontam que a maioria das mulheres "vivenciou experiências de descaso e desrespeito e algumas já esperavam sofrer algum tipo de maltrato antes mesmo do atendimento" (AGUIAR;D’OLIVEIRA, 2011, apud MUNIZ;BARBOSA, 2012, p. 5). A Fundação Perseu Abramo aponta que "uma em cada quatro mulheres é vítima de violência obstétrica durante o parto no Brasil" (POMPEO, 2014). Tais estatísticas evidenciam o quanto 
a ampliação da discussão sobre a Violência Obstétrica precisa ser urgentemente efetivada dentre os usuários dos serviços de Saúde, principalmente os de atenção especializada ao parto.

\title{
2 AUTONOMIA FEMININA EM CHEQUE
}

Para que os direitos reprodutivos possam ser exercidos em consonância com a política de Planejamento Familiar, Zorzam (2013, p. 45) aponta que é necessário atingir "o exercício concreto da cidadania e a abolição das injustiças sociais". De acordo com a legislação vigente, o Planejamento Familiar consiste em parte "integrante do conjunto de ações de atenção à mulher, ao homem ou ao casal, dentro de uma visão de atendimento integral à saúde" (BRASIL, 1996). Isto reforça que os direitos reprodutivos referem-se não apenas ao cidadão, individualmente, mas ao núcleo familiar, pois "a gravidez e o parto são eventos sociais que integram a vivência reprodutiva de homens e mulheres" (BRASIL, 2001, p. 9).

No entanto, há de se considerar que, pautados nos traços de uma sociedade "patriarcal, capitalista e androcêntrica" (MUNIZ;BARBOSA, 2012, p. 1), os direitos reprodutivos se consolidam de forma desigual para homens e mulheres. Reitero o questionamento de Saffioti (2005, p. 39) e também me indago se em algum momento da história houve igualdade social entre homens e mulheres. "Esta interrogação teria, muito seguramente, dado outro destino à valorização da importância do conceito de patriarcado na descrição e na explicação da inferioridade social das mulheres" (SAFFIOTI, 2005, p.39).

A posição social ocupada pela mulher e as desigualdades que se estabelecem nas relações entre homens e mulheres favorecem a compreensão de que "as relações de poder se exercem de maneira transversal na sociedade, o que faz com que existam diferentes experiências de ser mulher, de ser homem e de vivência da violência" (PASINATO, 2011, p. 239). Assim, "entendemos que não se pode compreender o fenômeno da violência como algo que acontece fora de uma relação de poder" (SANTOS;IZUMINO, 2005, p. 153). Diante disto, o desenvolvimento do movimento feminista representa uma relevante estratégia para a potencial efetivação dos direitos das mulheres em nosso país, tendo em vista que:

\begin{abstract}
a literatura sobre violência contra as mulheres tem suas origens no início dos anos 80 , constituindo uma das principais áreas temáticas dos estudos feministas no Brasil. Esses estudos são fruto das mudanças sociais e políticas no país, acompanhando o desenvolvimento do movimento de mulheres e o processo de redemocratização (SANTOS;IZUMINO, 2005, p. 147).
\end{abstract}

Considerando que o acesso à política de Saúde não se apresenta igualitário mediante à conceituação das desigualdades de gênero, torna-se possível identificar que a Violência Obstétrica também se encontra envolta de questões de gênero, que são culturalmente perpetuadas na sociedade. "O uso da categoria gênero introduz nos estudos sobre violência contra as mulheres uma nova terminologia para se discutir tal fenômeno social, qual seja, a expressão "violência de gênero" (SANTOS;IZUMINO, 2005, p. 148). Este conceito permite "compreender as múltiplas e distintas formas de relações entre homens e mulheres, que incluem valores, símbolos e linguagens presentes nas formações culturais" (ZORZAM, 2013, p.26). Desta forma, se torna prudente considerar que:

\footnotetext{
as desigualdades somadas às injustiças sociais, que marcam a vida cotidiana das mulheres, representam um grande ônus não só para elas, mas para a população como um todo, visto que não se pode conceber um mundo - mais democrático e mais justo - sem desenvolvimento humano, econômico, social e cultural. No dia-a-dia da vida percebe-se como as desigualdades, reforçadas por injustiças sociais, geram consequências que engendram dinamicamente para a formação de um círculo vicioso. O resultado deste processo é a falta de autonomia e poder, com maior ênfase para o gênero feminino (SOUZA;TYRRELL, 2006, p. 50).
}

No que tange ao atendimento especializado ao parto, percebe-se que, na contramão das premissas do parto humanizado, o que prevalece são as relações desiguais produzidas e reproduzidas entre profissionais e usuários. 
A Violência Obstétrica "tende a ser naturalizada, banalizada a ponto da mulher não se reconhecer como vitima, pois a naturalização é uma característica do cotidiano”. (DELFINO, 2016, p. 3).

O período gestacional e o advento do parto representam espaços de naturalização da violência contra a mulher, "no qual a mulher é tratada como mero sujeito secundário do nascimento de seu filho, sem atenção às suas necessidades e, muitas das vezes, com atos atentatórios à sua integridade física e moral" (CUNHA, 2015, p.8). Centralizando a atenção em um modelo "curativo, o período gestacional passa a ser tratado como doença, patologia que deve ser controlado pelo poder médico" (DELFINO, 2016, p. 07). Assim, ressalta-se que:

A violência obstétrica é ainda pouco reconhecida enquanto um ato violento, pois no mesmo momento que ela ocorre, as mulheres estão vivenciando marcantes emoções, que as fazem se calar, sendo necessário abordar os direitos da mulher durante a gestação, parto e pós-parto, especialmente nas consultas de pré-natais, onde tem-se a oportunidade de abordar os variados assuntos e, instrumentaliza-la para à tomada de decisões no que se refere ao seu corpo e a sua parturição, e que ela possa argumentar e denunciar situações de desrespeito (ANDRADE;AGGIO, 2014, p. 6).

No entanto,

A equipe multiprofissional geralmente espera que a parturiente tenha um tipo de comportamento contido, racional e sem expressões de dor frente ao parto. Os momentos mais críticos, quando as atitudes da parturiente fogem à expectativa do profissional, são aqueles mais propícios à violência simbólica e ao desrespeito aos seus direitos (FRANCA, et al., p. 3).

Por isto, as expectativas de acolhimento, cuidado e atenção no momento do parto podem se transformar em sentimentos de medo e acuação, que transformam o parto em um advento opressor e traumático. "O excesso de intervenções consideradas danosas à integridade física e psíquica contribuiu para a estigmatização do parto como um símbolo de sofrimento e opressão das mulheres" (MUNIZ;BARBOSA, 2012, p. 9). Na área da Saúde,

a violência institucional decorre das relações sociais marcadas pela sujeição dos indivíduos. O não reconhecimento das subjetividades envolvidas nas práticas assistenciais, no interior de uma estrutura caracterizada pela rigidez hierárquica, controle, ausência de direitos ou recurso das decisões superiores; pela forma de circulação da comunicação apenas descendente, pela disciplina autoritária e pelo descaso com relação aos aspectos humanísticos fizeram do hospital um lugar onde as pessoas são tratadas como coisas e prevalece o não respeito à sua autonomia e a falta de solidariedade (SOUZA, 2014, p. 18-19).

As relações de poder estabelecidas entre a equipe profissional e as pacientes vivenciando o período gestacional ou aguardando pelo momento do parto consistem em exemplos "de como o sistema de normas e valores que se estabelece na formação médica nega formalmente à mulher o controle sobre seu corpo e assim lhe nega a estatuto de sujeito livre e autônomo que a define como cidadã" (HOTIMSKY, 2009, p.10). Desta forma, as mulheres se tornam "cúmplices da violência que recebem [...], mas sua cumplicidade não se baseia em uma escolha ou vontade, já que a subjetividade feminina é destituída de autonomia (SANTOS;IZUMINO, 2005, p. 150).

Desta maneira, podemos considerar que o momento do parto pode equivaler a um fenômeno de violação dos direitos reprodutivos, de dignidade da pessoa humana e de liberdade das usuárias, contrários aos ideais de humanização dos serviços e do parto humanizado.

\section{PESQUISA}

A pesquisa "Violência Obstétrica e a Violação de Diretos Reprodutivos", aprovada pelo Comitê de Ética do Centro Universitário de Volta Redonda por meio do parecer número 2.114.701, emitido no dia Doze de Junho de 2017 (Certificado de Apresentação da Apreciação Ética - CAAE- número 67255517.8.0000.5237), consiste 
em parte da dissertação apresentada para a obtenção do título de Mestre do Mestrado Profissional em Ensino em Ciências da Saúde e do Meio Ambiente.

Para a realização deste estudo, adotou-se o método de pesquisa qualitativa, que se faz importante "entre as várias possibilidades de se estudar os fenômenos que envolvem os seres humanos e suas intrincadas relações sociais, estabelecidas em diversos ambientes" (GODOY, 1995, p. 21). Utilizou-se também o estudo de série de casos, que "tem por objetivo proporcionar vivência da realidade por meio da discussão, análise e tentativa de solução de um problema extraído da vida real" (GODOY, 1995, p. 25).

O universo analisado consiste em um programa de orientação à gestante, desenvolvido em um Município do interior do Estado de São Paulo. Considerando que existem vínculos fortalecidos entre a pesquisadora e os participantes da pesquisa, que participaram do referido Programa pelo período de dezoito meses, utilizou-se o instrumento da entrevista, que "trata-se de um diálogo orientado que busca, através do interrogatório, informações e dados de pesquisa" (LIBERALI, 2008, p. 54). Os dados foram obtidos em domicílio, em horário oportuno agendado previamente e as entrevistas foram gravadas, facilitando assim a transcrição dos relatos.

\section{RESULTADOS E DISCUSSÕES}

O formulário desenvolvido para a realização da pesquisa contém seis questionamentos que buscaram explorar as vivências de Violência Obstétrica de onze mulheres que participaram do programa de orientação à gestante e foram convidadas a participar deste estudo. As perguntas realizadas nos momentos das entrevistas foram: 1) Relate sua história de vida e a história da sua gestação (se houve planejamento, se o casal estava utilizando alguma forma de contracepção e como a notificação da gestação foi recebida pela família); 2) Relate as condutas profissionais as quais você foi submetida ao longo da realização do pré-natal, durante o parto e após o nascimento do seu filho; 3) Ao analisar seu discurso, você consegue reconhecer que foi vitima de algum tipo de violência durante o pré-natal ou no parto? Qual ou quais?; 4) Você já ouviu a terminologia "Violência Obstétrica"? Qual seu conhecimento sobre o assunto? Acredita que tenha sido vítima deste tipo de violência?; 5) Em caso afirmativo, suas experiências foram oficializadas na Secretaria de Saúde ou Ministério Público?; 6) Como você e sua família conseguiram superar a Violência Obstétrica?

O objetivo geral da pesquisa consiste na identificação da ocorrência e quais os tipos de violência estão presentes nos discursos de vivências dos processos de pré-natal e do fenômeno do parto das mulheres que participam deste Programa e que em algum momento, relataram ter sofrido com ações abusivas e coercitivas por parte de profissionais da Saúde.

Com as informações objetivas por meio das entrevistas, foi possível identificar que, ao longo da realização das consultas de pré-natal, as principais expressões de Violência Obstétrica foram: o agendamento de cesariana para a realização do procedimento da laqueadura tubária, as frases ofensivas e a negligência médica. No parto, as principais formas de violação de direitos representam as frases ofensivas e a peregrinação por leitos. Após o parto, a mais expressiva representação da violação de direitos da mulher consiste na não confirmação do profissional sobre a realização do procedimento da laqueadura tubária, solicitado e acordado previamente entre o médico e a paciente.

Dentre as onze mulheres entrevistadas, apenas duas conheciam a terminologia "Violência Obstétrica" e a principal forma de obtenção deste conhecimento foi por meio de buscas na internet. Após a abordagem da temática, sete mulheres se reconheceram enquanto vitimas deste tipo de violência.

Após explicações sobre o conceito de Violência Obstétrica, duas mulheres não se reconheceram como vítimas deste tipo de violência, sendo que uma se sentia responsável pelos atendimentos ofertados pela equipe 
de saúde. Tal sentimento advém do fato de esta mulher ter evidenciado seus sentimentos em relação à gestação, não planejada e indesejada pela família.

As situações vivenciadas ao longo das consultas de pré-natal, durante e após o parto resultaram no medo de dez mulheres em gerarem outros filhos. O parto se tornou um evento tão traumatizante, que estas mulheres abandonaram o desejo de aumentar a família e ter mais filhos, evitando desta forma passar novamente por situações equivalentes. Apenas uma mulher entrevistada apresentou o desejo de gerar mais uma criança, justificada pelo fato de que foi submetida ao procedimento de laqueadura tubária no momento do parto, sem o seu consentimento ${ }^{3}$. Diante deste quadro, esta mulher luta pelo desejo de reverter a laqueadura tubária e engravidar novamente.

\section{FATORES QUE DIFICULTAM O RECONHECIMENTO ENQUANTO VÍTIMA DE VIOLÊNCIA OBSTÉTRICA}

A pesquisa realizada apontou que uma mulher se sentiu "sem importância" durante a realização do pré-natal e no momento do parto. Esta mulher se sentia vítima de "descaso" por parte dos profissionais responsáveis por seus cuidados e não vítima de algum tipo de violência. Muitas mulheres atribuem o atendimento desumanizado à "falta de sorte e isto demonstra a percepção de que o bom atendimento é considerado raro e não faz parte da rotina da assistência ao parto" (CIELLO, et. al., 2012, p. 130). Este tipo de situação vivenciada pelos usuários da política de Saúde nem sempre é percebida como violação de direitos, haja vista que "a violência institucional ${ }^{4}$ nem sempre se manifesta como violência, passando muitas vezes despercebida, não pelo fato de ser menos cruel, mas pela forma sutil com que se apresenta" (SOUZA, 2014, p. 19).

Três mulheres entrevistadas acreditam que a Unidade Básica de Saúde deveria disponibilizar espaços de discussões sobre a temática da Violência Obstétrica. Porém, as mulheres informaram que este assunto não representava uma pauta a ser debatida ao longo das consultas de pré-natal. Para averiguar esta afirmação, foram realizadas visitas às dezessete Unidades Básicas de Saúde que compõem a rede de Saúde deste Município. Foi possível identificar a existência de inúmeros cartazes explicativos afixados no mural de informações destas Unidades. Os cartazes continham informações sobre doenças e campanhas, tais como: Hanseníase, Hepatite, AIDS, Tuberculose, Gripe, Teste rápido, Meningite, Dengue e Diabetes. Das dezessete Unidades, apenas uma apresentava, afixada ao mural informativo, um cartaz sobre o preenchimento correto da caderneta de gestante e algumas estratégias sobre como amenizar as dores do parto.

As enfermeiras responsáveis pelas Unidades foram questionadas sobre a inexistência de cartazes sobre as ações e condutas que caracterizam a Violência Obstétrica e as dezessete profissionais afirmaram que nenhum material com este teor foi entregue para distribuição nas Unidades de Saúde do Município desde que elas haviam assumido os equipamentos. As informações que deveriam ser discutidas neste espaço e que poderiam favorecer às usuárias o reconhecimento de ações profissionais que caracterizam a Violência Obstétrica não são veiculadas, o que limita as possibilidades de reconhecimento das mulheres enquanto vítimas deste tipo de violência.

Outro fator evidenciado por uma mulher entrevistada consiste na inexpressiva quantidade de legislações promulgadas sobre a Violência Obstétrica no Brasil. Em todo o território nacional, existe apenas uma lei que "dispõe sobre a implantação de medidas de informação e proteção à gestante e parturiente contra a violência obs-

3 Esta mulher foi submetida ao procedimento de laqueadura tubária durante o parto do terceiro filho. Ao longo da realização do pré-natal, o médico abordava a possibilidade de realizar o procedimento de forma recorrente, quase coercitiva. A mulher, por sua dez, desejava constituir sua família com cinco filhos e expressava este desejo ao obstetra de referência. Mesmo que a Lei do Planejamento Familiar (Lei nº 9.263/96) aponte no Art. $2^{\circ}$ que "é proibida a utilização das ações a que se refere o caput para qualquer tipo de controle demográfico" (BRASIL, 1996), a quantidade de filhos daquela mulher era constantemente questionada pelo profissional. Desta forma, o procedimento foi realizado sem o consentimento da mulher, mas apoiado pela sua irmã, que compartilhava do mesmo posicionamento que o médico.

4 Sobre a violência institucional, Souza (2014, p. 21) aponta que "no âmbito dos serviços de saúde, a violência institucional é aquela onde há a reprodução das desigualdades nas relações de poder presentes no espaço social para o âmbito hospitalar" (SOUZA, 2014, p. 21). 
tétrica" (FLORIANÓPOLIS, 2017). A lei nº 17.097, de 17 de janeiro de 2017 tem vigência no estado de Santa Catarina. Esta mulher acredita que se tivesse acesso a algum tipo de legislação que tratasse exclusivamente sobre esta temática, o seu reconhecimento enquanto vítima poderia ser facilitado.

\section{CONSIDERAÇÕES FINAIS}

As ações desenvolvidas para o exercício do Planejamento Familiar se encontram permeadas por relações de poder. Para além das questões de gênero (que justificam e reforçam as desigualdades de responsabilidades entre os sexos e determinam papeis sociais diferentes para homens e mulheres), foi possível perceber a predominância de relações desiguais de poder estabelecidas entre os profissionais da política de Saúde e os usuários dos serviços. Esta relação de poderio favorece a perpetuação da violência institucional, que dificilmente é reconhecida como violação de direitos, principalmente quando realizada no momento do parto. Considerando todos as questões psicológicas que envolvem esta etapa da vida da mulher, a violência institucional pode passar despercebida e por isto acaba por se tornar rotineira e habitual no ambiente hospitalar.

As dificuldades do reconhecimento de uma mulher enquanto vítima de Violência Obstétrica envolve principalmente a falta de conhecimento sobre esta temática e sobre os direitos de cidadania em sua complexidade. As poucas legislações promulgadas para o combate da Violência Obstétrica também foram apontadas como uma das principais causas da dificuldade em se reconhecer como vítima deste tipo de violência contra a mulher. Diante disto, podemos considerar que o período gestacional e o parto representam momentos propícios para a disseminação da violência, pois as mulheres tendem a ter sua autonomia negada em detrimento das desigualdades apontadas anteriormente.

As ações e condutas mencionadas pelas entrevistadas apontam que os princípios do Sistema Único de Saúde têm sido gravemente violados, uma vez que os serviços de atendimento especializado ao parto podem ferir a autonomia, a integridade física e psicológica e o poder de decisão sobre o próprio corpo da mulher. Desta forma, o parto pode se tornar um momento opressor e traumático na vida das mulheres e isto pode interferir diretamente na opção de ampliar ou não a sua família, ou seja, de exercer o Planejamento Familiar.

\section{REFERÊNCIAS}

ANDRADE, Briena Padilha; AGGIO, Cristiane de Melo. Violência Obstétrica: a dor que cala. Anais do III Simpósio Gênero e Políticas Públicas - Universidade Estadual de Londrina. 2014.

BARBOZA, Luciana Pereira; MOTA, Alessivânia. Violência Obstétrica: vivências de sofrimento entre gestantes do Brasil. Revista Psicologia, Diversidade e Saúde. Salvador. 2016.

BRASIL. Lei de Planejamento Familiar. Lei nº 9.263 de 12 de Janeiro de 1996.

BRASIL, Ministério da Saúde. Manual do parto, aborto e puerpério: assistência humanizada à mulher. Brasília: Ministério da Saúde, 2001.

BRASIL. Defensoria Pública do Estado de São Paulo. Cartilha. Violência Obstétrica: você sabe o que é? São Paulo. 2014.

CIELLO, Cariny, et. al. Dossiê da Violência Obstétrica. "Parirás com dor". Dossiê elaborado pela Rede Parto do Princípio para a CPMI da Violência Contra as Mulheres. 2012. 
CUNHA, Camila Carvalho Albuquerque. Violência obstétrica: uma análise sob o prisma dos direitos fundamentais. Monografia. Faculdade de Direito. Universidade de Brasília, 2015.

DELFINO, Cristiane Cordeiro da Silva. Violência Obstétrica e Serviço Social: limites e desafios na atualidade. II Congresso de Assistentes Sociais do Rio de Janeiro. 2016.

FLORIANÓPOLIS. Lei de combate à Violência Obstétrica. Lei nº 17.097, de 17 de Janeiro de 2017.

FRANCA, Bruna Suellen da Silva; FIGUEIREDO, Janaína Dutra; BARBOZA, Jenifer Monteiro; SOUZA, Danielle Costa da; ZAPPONI, Ana Luiza Barreto. Violência institucional obstétrica no ambiente hospitalar. Revista Rede de Cuidados em Saúde.

GODOY, Arilda Schmidt. Pesquisa Qualitativa - Tipos Fundamentais. Revista de Administração de Empresas. São Paulo, v. 35, nº 3 - 1995.

HOTIMSKY, Sonia Nussenzweig. A violência institucional no parto no processo de formação médica em obstetrícia. I ENADIR - Encontro Nacional de Antropologia do Direito Universidade de São Paulo - 20 e 21 de agosto de 2009.

LIBERALI, Rafaela. Metodologia científica prática: um "saber-fazer" competente da saúde à educação. Florianópolis, 2008.

MUNIZ, Beatriz Maia de Vasconcelos; BARBOSA, Ruth Machado. Problematizando o atendimento ao parto: cuidado ou violência? La Habana, 2012.

PASINATO, Wânia. "Femicídios” e as mortes de mulheres no Brasil. Cadernos Pagu. No37. Jul-Dez. 2011.

POMPEO, Carolina. Uma em cada quatro mulheres sofre violência obstétrica no Brasil. 26/09/2014. Disponível em: http://www.gazetadopovo.com.br/vida-e-cidadania/uma-em-cada-quatro-mulheres-sofreviolencia-ostetrica-no-brasil-ee5jkxiutgeb18bwkud2ozhhq Acesso em 09 de Fevereiro de 2016.

SAFFIOTI, Heleieth I B. Gênero e Patriarcado: a necessidade da violência. In: MARTIN, Marcia Castillo; OLIVEIRA, Suely de (Org.). Marcadas a ferro: violência contra a mulher. Uma visão multidisciplinar. Brasília. Secretaria Especial de Políticas para as mulheres, 2005, p. 35-76.

SANTOS, Cecília Macdowell; IZUMINO, Wânia Panitato. Violência contra as Mulheres e Violência de Gênero: Notas sobre Estudos Feministas no Brasil. E.I.A.L., Vol. 16 - No 1 (2005).

SOUZA, Kleyde Ventura de. TYRRELL, Maria Antonieta Rubio. Os fatos e atos relacionados ao (difícil) exercício dos direitos sexuais e reprodutivos: em recortes, o processo de viver de um grupo de mulheres de classes populares. Texto Contexto Enfermagem. Florianópolis, 2006.

SOUZA, Karina Junqueira de. Violência institucional na atenção obstétrica: proposta de modelo preditivo para depressão pós-parto. Faculdade de Ciências da Saúde. Universidade de Brasília. Dissertação de Mestrado. Brasília 2014.

ZORZAM, Bianca Alves de Oliveira. Informação e escolhas no parto: perspectivas das mulheres usuárias do SUS e da saúde suplementar. Universidade de São Paulo. Faculdade de Saúde Pública. Dissertação de mestrado. 2013. 